\title{
Examining the Relationship between Service-Learning Participation and the Educational Success of Underrepresented Students
}

\author{
Wei Song \\ University of Minnesota \\ Isabel Lopez \\ University of Minnesota
}

\author{
Andrew Furco \\ University of Minnesota \\ Geoffrey Maruyama \\ University of Minnesota
}

\begin{abstract}
Underrepresented students have been identified as being less likely to attain a college degree than their majority counterparts. Service-learning (SL) offers students an opportunity to engage in community work and improve skills that might contribute to their educational success in college. The present study aimed to investigate the impact of SL courses on students' academic outcomes (fourth-year cumulative GPA) and persistence (fourth-year cumulative units earned, retention, and graduation) at a large Midwestern university, with a focus examining service-learning's impact on underrepresented students. Results showed that SL participation was positively related to underrepresented students' cumulative GPA, retention, and graduation, but was not related to units earned. The relationship between SL and academic outcomes, however, were not consistent across the colleges included in the study. In some colleges, SL had negative relationships with underrepresented students' academic outcomes and persistence. The differential findings across the colleges suggest that university-wide studies of SL should take into account particular practices within SL courses that promote and limit underrepresented students' capacity to optimize educational outcomes.
\end{abstract}

Higher education institutions are under increasing pressure to increase college completion rates, particularly for students from underrepresented groups, namely, students of color, first-generation college students, and students from low-income economic backgrounds. In 2015, the U.S Census reported that $33 \%$ of the population in the United States between the ages of 25 to 29 had completed a bachelor's degree or higher, with only $11 \%$ of Black and 10\% Hispanic individuals, compared to $21 \%$ of non-Hispanic White and $38 \%$ of Asian individuals (Ryan \& Bauman, 2016). There is a persistent and growing gap in degree attainment between students from ethnic minority groups and their majority counterparts (Lavin \& Crook, 1990; Astin \& Oseguera, 2005). Similarly, low-income and first-generation students are less likely to go to a four-year college than their more privileged peers (Cahalan \& Perna, 2015). Even among those who go to college, the disparity in college completion still exists (Engle \& Tinto, 2008). Underrepresented students have been identified as being at greater risk with respect to persistence and degree attainment than their peers (Terenzini, Springer, Yaeger, Pascarella, \& Nora, 1996; Thayer, 2000).

Service-learning (SL) has become increasingly popular within universities as a means to engage students and promote students' learning and persistence. SL has many aims, and increasing evidence using different study designs reveals the potential of SL to have a positive effect on college students' academic, social, personal, civic and professional development (Celio, Durlak, \& Dymnicki, 2011; Eyler, Giles, Stenson, \& Gray, 2001; Warren, 2012; Yorio \& Ye, 2012). One of the noted outcomes of SL is its potential to enhance the mediators of college student persistence and educational success, including academic engagement, sense of belonging, and motivation for learning (Batchelder \& Root, 1994; Furco, Jones-White, Huesman, $\&$ Gorny, 2016). Given that underrepresented students are less likely to possess these mediators of educational success, one might hypothesize that SL can be effective in closing present attainment gaps between underrepresented students and nonunderrepresented students by enhancing the mediators of educational success through SL.

However, the evidence regarding the differential benefits of SL for underrepresented students remains scant. We hypothesize that of all of the high impact practices associated with enhanced student engagement and learning (Kuh, 2003), SL may have the greatest potential for promoting underrepresented students' educational success because 
insofar as it offers them opportunities to connect with diverse communities and address societal issues that matter to them. To test this hypothesis, the current study sought to compare the effects of SL on the educational success of underrepresented and non-underrepresented students. Based on Brofenbrenner's (1979) theory of social ecology, servicelearning, which engages students in actions that link their college life to community issues through course-based community-based learning experiences, has the potential of mitigating feelings of uncertainty and disconnection that underrepresented students often feel when entering college (Terenzini at al., 1996). Using data from a large Midwestern university, we examined the relationship between underrepresented and non-underrepresented students' participation in SL and their academic outcomes as measured by fourth-year cumulative GPA, units earned, retention, and graduation rates. The students at this university elected the courses in which they enrolled, and in turn voluntarily participated (or not participated) in SL. Consequently, there was no option for us to create experimental conditions that randomly assigned students to treatment (SL) or control (non-SL) courses. To address this limitation, we used propensity score matching (PSM) methods (full matching) to create comparable SL and non-SL groups for both underrepresented and non-underrepresented student populations. PSM approaches are designed to help minimize selection bias and pre-existing differences between treatment and comparison groups on a series of key background variables (e.g., d'Agostino, 1998).

Studies have revealed that SL can have a positive influence on the personal, social, civic, career, and academic growth of students (Conway, Amel, \& Gerwien, 2009; Eyler et al., 2001). For the present study, we focused specifically on academicrelated outcomes. In particular, we investigated the outcomes of service-learning in the areas of students' academic performance and persistence. Performance pertains to the students' mastery of course subjects, typically measured by cumulative grade point average (GPA). Persistence is indicated by cumulative units earned and continuous enrollment. We also examined whether students completed their degree in four years, which is considered another positive indicator of persistence (Pascarella \& Terenzini, 2005). A diverse array of college programs and pedagogies, such as SL, are designed to integrate students into universities, academically and socially, in order to increase students' performance, persistence, and ultimately, graduation (Goodman \& Pascarella, 2006; Pascarella \& Terenzini, 2005). In the present study, we examined how course-based SL designed to integrate students into community as part of their coursework might affect campus engagement, with the goal of investigating the relationship between students' participation in SL and educational success.

\section{Educational Success and Its Predictors}

Several theories explain the important role that students' academic and social integration (e.g., student-faculty interaction, peer interaction, and participation in campus activities) plays in enhancing students' commitment to the college and making efforts toward degree attainment (e.g., Tinto, 1993). Both Astin's (1984) Theory of Involvement and Bean's $(1980,1983)$ student attrition theory highlight the critical role of behavioral mechanisms of involvement in students' educational outcomes. Astin argues that highly involved students who devote a considerable amount of physical and psychological energy to academic activities are more likely to achieve desired learning and development outcomes compared to uninvolved students. What individuals do and how they behave determine the impact of involvement on student persistence. Bean provides empirical evidence showing that students' interactions with faculty and the time spent on academic work outside of class play an important role in students' persistence process. In contrast, Tinto's (1993) Interactionalist Model of Student Departure recognizes the importance of both perceptual and behavioral components of academic and social integration in college persistence. Empirical studies support Tinto's assertion that students' behavioral involvement and perception of social and academic integration are related to higher levels of college persistence not only directly (Berger \& Milem, 1999), but also indirectly via students' academic goals and institutional commitment (Braxton, Sullivan, \& Johnson, 1997).

No matter if phrased as "integration" or "involvement," theories and evidence suggest that students who are successfully socialized within a campus's academic and social communities are more likely to persist. In other words, students' academic and social engagement is central to their success (Pascarella \& Terenzini, 2005). Academic and social integration leads to institutional fit and commitment, which enables students to overcome obstacles and persist in college. The research and theories, however, do not explain the underlying mechanisms by which the activities increase academic and social integration or reduce dropout rates.

Bean and Eaton's (2001) psychological model of college student retention helps explain why some students integrate academically and socially while others do not. The model describes psy- 
chological attributes that contribute to academic performance and social integration: self-efficacy; coping strategies; and locus of control (i.e., attribution). Specifically, students make efforts toward degree completion if they believe that they are capable, can cope with problems using approaching rather than avoiding methods, and see themselves in control of their successes and failures. These key attributes have been examined in many studies. For example, a meta-analysis by Robbins et al. (2004) concluded that academic-related skills ${ }^{1}$ and academic self-efficacy are strongly related to retention and academic performance (i.e., GPA), which supports Bean and Eaton's hypothesis. In addition, consistent with the premises of retention theories, academic goals, institutional commitment, social involvement, and social support also have been found to be positively related with student retention and GPA. This suggests that involvement in college and the growth in psychological attributes both contribute to students' educational success.

\section{Experiences of Underrepresented Students}

In our study, underrepresented students include students of color, students from low-income families, and first-generation college attendees. Underrepresented students are more likely to withdraw from college and tend to have poorer achievement than students who are White, from a higher SES background, and with college-educated parents (Engle \& Tinto, 2008; Pascarella \& Terenzini, 2005). They face unique challenges and obstacles on the path to educational attainment and persistence. First, their family's social-economic status may pose limitations for them to achieve success (Bridges, Kinzie, Nelson Laird, \& Kuh, 2008; Terenzini, Cabrera, \& Bernal, 2001; Yeh, 2002). For instance, students from lowincome families are less likely to receive financial support from parents. Family obligations and job responsibilities may limit their participation in academic learning and their time spent on schoolwork. Second, underrepresented students tend to have lower levels of academic preparation for college due to lower academic achievement and underdeveloped academic skills in high school (Terenzini, Cabrera, \& Bernal, 2001; Yeh, 2002; Zalaquett, 1999). Third, studies have found that underrepresented students, especially first-generation students, possess less knowledge about the culture, operations, and nature of postsecondary education (e.g., styles of discussion and communication; Yeh, 2002) compared to non-underrepresented students. All these factors increase difficulty for students and negatively influence their potential for educational success. Therefore, it is important that we examine potential factors that may help underrepresented students overcome the barriers they experience in college.

In addition, underrepresented students are generally less engaged in academic and social activities (Lohfink \& Paulsen, 2005; Pascarella, Pierson, Wolniak, \& Terenzini, 2004; Terenzini, Cabrera, $\&$ Bernal, 2001). This is concerning because there is a positive relationship between engagement in academic-oriented activities and desired academic outcomes, such as better grades, higher retention rates, and educational gains (Kuh et al., 2005; Pascarella \& Terenzini, 2005). It also has been suggested that such engagement benefits underrepresented students more than other students (Lohfink \& Paulsen, 2005; Pascarella et al., 2004; Wasley, 2006). For instance, African American students who had the same level of engagement in educationally purposeful activities as their White peers had higher probabilities of returning to college in their second year (Kuh, Cruce, Shoup, Kinzie, \& Gonyea, 2008). The earlier that students get involved, the higher the rate of retention; this is especially true for African American students (Berger \& Milem, 1999). Effective educational practices, particularly collaboration with peers and interactions with faculty, help underachieving students catch up with high achieving students. The more engaged underrepresented students become, the better grades they attain, and the higher their likelihood to continue in college.

The socialization processes with faculty and peers also allow underrepresented students to improve in college adjustment. They gain social support and social capital that help counteract risk factors they face in college. Peer support is an important predictor of higher college GPA and adjustment of ethnic minority first-generation students, above and beyond the relation of family support (Dennis, Phinney, \& Chuateco, 2005). Latino college students who received social support mostly from peers in their freshmen year reported a higher degree of college and social adjustment (Hurtado, Carter, \& Spuler, 1996; Rodriguez, Mira, Myers, Morris, \& Cardoza, 2003).

Moreover, racial/ethnic identity influences student retention (Johnson \& Arbona, 2006). Having a strong sense of self and achieved ethnic identity equip underrepresented students to make sense of the threats to achievements in their academic lives (Louis \& Liem, 2005; Phinney, 1993). In their study, Taylor \& Howard-Hamilton (1995) found that African American students who were more involved in clubs, organizations, and sports, who had more interactions with faculty, staff, and peers, and who worked on campus and participated in community service were more likely to develop a posi- 
tive ethnic identity. A high level of involvement in college may be especially beneficial for minority students to achieve educational success by establishing a positive identity.

\section{Service-learning and Educational Success}

There is a broad literature behind the potential positive outcomes of SL for students in higher education. By providing students with opportunities to link theory to practice, test the theory in new situations (Jacoby \& Associates, 1996), and increase their interactions with faculty and peers (Eyler \& Giles, 1999; McKay \& Estrella, 2008), SL has the potential to produce positive and direct effects on college students' academic outcomes and their development of study skills and habits (Corbett \& Kendall, 1998). Results of meta-analyses involving undergraduate students have shown that, when elements of high quality SL practice are in place, SL promotes students' learning outcomes, measured by exam scores, student self-report, assignment scores, or cognitive measures (Warren, 2012). In addition, compared to peers who do not participate in SL, SL participants have shown gains in problem-solving skills (Greenberg, 1997; Moely et al., 2002), higher order thinking (Eyler \& Giles, 1999), moral reasoning (Bernacki \& Jaeger, 2008; Boss, 1994), and leadership and communication skills (Eyler \& Giles, 1999), as well as spend more time on schoolwork (Astin \& Sax, 1998). SL has also been found to increase students' subjectmatter interest, which is very important for enhancing students' learning and understanding of course materials (Astin, Vogelgesang, Ikeda, \& Yee, 2000; Steinke \& Buresh, 2002).

We have discussed the important role academic and social integration plays in mediating students' educational outcomes. Ample evidence has shown that SL also provides opportunities for development of several factors that mediate educational success (Gullicks, 2006). For example, SL has been found to increase student-faculty interactions and peer interactions (Astin \& Sax, 1998; Sax \& Astin, 1997), as well as engagement in classroom experiences (Astin et al., 2000) and social activities (Lee, Olszewski-Kubilius, Donahue, \& Weimholt, 2008). Studies have also found SL to be positively related to reduced feelings of isolation among participating students (Greenberg, 1994; Kelly, 2013). Nunez (2009) found that students' participation in community-based experiences exerted a direct and positive effect on Latino/a students' sense of belonging to the institution, as well as an indirect effect via the obligation to give back to the community. The development of a sense of belonging re- duced the likelihood of attrition for college students (Bean \& Eaton, 2001).

In terms of the development of self, SL has been related to the development of self-confidence (e.g., Vogelgesang \& Astin, 2000), self-efficacy (Austin et al., 2000; Simons \& Cleary, 2006; Stewart, 2008), and academic motivation (Flournoy, 2007). According to Bean and Eaton's (2001) psychological model of college retention in the context of SL, all these factors may contribute to and potentially enhance students' academic learning and retention in college. For instance, via SL participation, students can gain academic and social self-efficacy through meaningful work and interaction with faculty and peers. Linking SL to Bean and Eaton's and other psychological models strengthens the theoretical basis for explaining the relationship between SL participation and college students' educational success.

Even though most of the evidence regarding the relationship between SL and students' educational success has not been built specifically upon underrepresented students, there is ample evidence to allow us to hypothesize that the positive educational outcomes of SL presented to date extend to underrepresented students. There are only a handful of empirical studies that have examined the relationship between participation in SL and underrepresented students' persistence and academic achievement in higher education (e.g. Chesler \& Vasques Scalera, 2000; Green, 2001, Yeh, 2010, York, 2016). Yeh (2010) conducted an exploratory qualitative study with six low-income, first-generation (LIFG) students who participated in a SL course with the objective of understanding how the SL experience impacted their retention. Yeh found that SL facilitated students' academic skills and understanding by developing social capital, self-efficacy, and coping strategies. SL students were also able to find personal meaning and values, which could exert a positive impact on college retention. Even though Yeh's study did not examine students' retention, her investigation supports the hypothesis that the aforementioned positive effects found in the SL literature can be extended to underrepresented students. To expand Yeh's research, our study includes ethnic minority students as part of the underrepresented group, with an eye toward investigating whether SL affects the educational success of underrepresented students in the same manner as it affects more privileged peers.

For his study, York (2016) used a mixed method approach to explore SL outcomes for low-income, first generation (LIFG) college students through analyses of data of more than 5,000 LIFG students from 87 institutions of higher education who were 
part of a national longitudinal data set maintained by UCLA's Higher Education Research Institute (HERI). His study included qualitative analyses of data collected from seven students who were interviewed to share their perspectives on how SL affected their critical consciousness and cognitive diversity. York's analyses of the HERI data found SL to have a significant and positive relationship to LIFG students' GPA.

Our study was part of a four-year U.S. Department of Education grant that aims to evaluate the impact of community engagement on students' academic achievement and persistence in higher education. Using matched treatment and comparison groups selected by the full matching approach of propensity score matching, the study investigated whether underrepresented students (students of color, first-generation, and/or low-income) at a large Midwestern university who participated in SL courses had better cumulative GPAs and units earned as well as higher probabilities of retention and graduation after four years when contrasted with comparable students at the university who did not participate in SL.

The SL activities were part of a campus-wide program operationalized through a campus-wide center that provides quality indicators and support for SL course development. Given that our study relied on existing data from the university's office of institutional research, we did not have access to data regarding the operationalization or quality level of individual service-learning courses. Given that the courses were facilitated through the institution's campus-wide service-learning center, we conducted the study with the assumption that the courses met at least the minimum level of SL quality promoted by the center; however, we acknowledge that it is likely that the quality of SL practice varied across courses, and in turn, students' experiences with SL was not equal. Within our data set, there was great variability in the implementation of the treatment across the courses and colleges. Unfortunately, without access to data regarding the specific SL practices that took place with each course, we were unable to control for or account for this likely variability.

\section{Method}

\section{Participants}

The current study analyzed four-year longitudinal data obtained from the university's institutional research office. The dataset includes detailed information of all students $(N=5,368)$ who entered the university in fall 2011, following them over a period of four years through summer 2015. The student population in this dataset was predominantly White $(76 \%)$ and female $(52 \%)$ with an average age of $18.14(S D=.49)$ years. With regard to underrepresented populations, this dataset included $16 \%$ Asian, $4 \%$ Black, 3\% Hispanic, and 2\% other non-White students, with $26 \%$ of the students being first-generation college students and $22.3 \%$ Pell Grant eligible.

Service-learning (SL) participants. About $51 \%$ $(n=2,731)$ of the students in the dataset enrolled in one or more courses that contained SL during their first four college years. They included 58\% female students; $25.9 \%$ students of color (15\% Asian; 6\% Black; 3\% Hispanic; and 2\% other non-White), $30 \%$ first-generation, and 26\% Pell Grant eligible.

Non-service-learning (Non-SL) students. About $49 \%(n=2,637)$ of the students did not participate in SL through the spring 2015 semester. This non-SL group included $46 \%$ female students; $23 \%$ students of color (17\% were Asian, 2\% Black, 2\% Hispanic, and $2 \%$ other non-White), $22 \%$ first-generation, and $18 \%$ Pell Grant eligible students. Overall, there was a lower percentage of underrepresented students in the non-SL group than in the SL group across all categories of underrepresentation.

\section{Data Analysis Procedures and Measures}

The data analyses were composed of three steps: (a) propensity score matching (PSM) with full matching to create the two groups to be compared; (b) weighted least square regression on students' fourth-year GPA and units earned; and (c) logistic regression on retention and graduation rates incorporating propensity weights. After securing matched groups, we conducted the first analyses using the entire sample. We then conducted within-college analyses due to the differences in the practices and availability of SL courses, as well as the characteristics of students across the university's seven admitting and enrolling colleges. Given that one college required all students to participate in SL (and therefore, a comparison group could not be secured), we dropped that college from our analysis and focused on the students enrolled in the six remaining colleges (i.e., Biology, Design, Agriculture, Liberal Arts, Science and Engineering, Management).

\section{Propensity Score Matching: Full Matching}

Although randomized control trials provide the "gold standard" for drawing causal associations in educational research (Donaldson, Christie, \& Mark, 2009), randomization was not achievable in our study because students largely select their own 
courses. To minimize self-selection bias and preexisting differences in student characteristics, we employed propensity score full matching to identify matched pairs of participants for treatment and control conditions. Full matching, developed by Rosenbaum (1991), creates a collection of matched sets. Each set consists of either a treated individual (a SL student) and any number of potential comparison individuals (i.e., a non-SL student), or a comparison individual (a non-SL student) and any number of treated (SL) individuals. Weights then adjust to equalize the samples. The advantages and illustrations of full matching have been discussed in detail by many scholars (e.g., Austin \& Stuart, 2015; Hansen, 2004; Stuart \& Green, 2008). We chose the full matching method based on its two merits: (a) it includes almost all the participants in the analysis, thus avoiding incomplete matching; and (b) it is effective in reducing the differences in the observed covariates that potentially confound the outcome.

Matching variables. For the matching process, we selected background variables that have been found to be related to educational outcomes. These variables included demographic variables (i.e., ethnicity, gender, age, United States Citizenship, international students, first-generation, and Pell Grant eligible) and students' previous academic performance (i.e., ACT composite scores). The university in which the study was situated accepts both ACT and SAT scores for admission. To adjust for this, we converted SAT scores to the ACT scale using ACT-SAT Concordance.

Procedure of full matching. The first step involved creating a propensity score for each student by regressing the treatment status (SL or not) on the demographic and test score variables. The propensity score represents the predicted probability of participating in SL. Then, based on individual propensity scores, we divided the full sample into a series of matched sets that contained either one SL student and multiple non-SL students, or one non-SL student and multiple SL students. To avoid large discrepancies in the ratios of treated to comparison individuals, we drew cases only where the two distributions overlapped (called common support), which is the area falling within the overall propensity score distribution. Lastly, each individual received a weight based on the number of comparison students in each set. Treated students received a weight of 1 ; comparison students received a weight proportional to the number of treated students divided by the number of comparison students. Those weights were incorporated in the following analyses.

\section{Regression Analyses After Full Matching}

Outcome variables. We examined the relationship of SL with four measures of students' fourthyear academic outcomes: (a) student cumulative GPA (ranging from 1 to 4) as of summer 2015; (b) total cumulative units earned as of summer 2015; (c) enrollment status in the fall 2015 ( 1 = enrolled, $0=$ not enrolled); and (d) graduation status by the fall 2015 ( 1 = graduated, $0=$ not graduated $)$.

We used weighted least square regression for the GPA and units earned by incorporating the weights generated by the full matching procedures. Weighted logistic regression was used for the enrollment and graduation status. The regression analyses were conducted in two parts: (a) including all matched students across and within colleges; and (b) focusing on the underrepresented students across and within colleges.

\section{Results}

\section{Checking Matching Effectiveness}

The primary goal of full matching is to minimize the bias in estimating the treatment effect. The quality of matches was diagnosed for the full sample and samples within colleges. Non-SL students did not differ from SL students by .25 standardized mean differences on any of the individual covariates, indicating that the groups are adequately matched and that propensity score methods are appropriate. (e.g., Austin, 2011b; Ho, Imai, King, \& Stuart 2007). Using the U.S. Department of Education's What Works Clearinghouse (WWC) standards, we controlled for background variables that had larger than .05 standardized mean differences between the groups after matching in the regression analyses. Because the relationship of other covariates with student outcomes were not the interest of the present study, we report only the effect of SL in the next section. Visually, histograms of propensity scores and standardized mean differences, as well as jitter graphs of individuals (Ho et al., 2007; Stuart, 2010) indicated a good balance of the two groups.

\section{Results of Regression Analyses}

Table 1 presents the results of students' fourthyear cumulative GPA, cumulative units earned, retention, and graduation status across the whole university and within colleges from weighted regression analyses. Results for underrepresented students and non-underrepresented are displayed in Table 2 and Table 3 from the same analyses. The beta coefficients and standard errors of SL partic- 
ipation are reported in the tables, plus the odds ratios from the weighted logistic regression.

University-wide effects. The first row of Table 1 shows university-wide effects of SL. Results support a positive and a significant relationship of SL with both underrepresented and non-underrepresented students' cumulative GPA $(B=.08, p<.001)$, retention $(B=.81, p<.001)$ and graduation $(B=.63, p<.001)$, but not units earned $(B=-.21, p=.748)$. These results find that participation in SL courses was associated with a better cumulative GPA after four years in college, and with a lower probability of dropping out of college and a higher probability of graduation after four years. The same pattern appeared for both underrepresented and non-underrepresented students (see Tables 2 and 3). With regard to units earned, however, there was a positive relationship with SL only for non-underrepresented students. In sum, the university-wide analyses suggest that, in general (with the exception of units earned), SL had a positive and significant relationship with students' educational success in college.
College-level findings. The association between SL participation and student academic outcomes was not consistent across colleges. GPA results revealed that among underrepresented students, participation in SL courses was positively related to GPA only for those students in Biology and Liberal Arts (see Table 2). Surprisingly, the students in the colleges of Design and Agriculture who participated in SL during the four years achieved lower GPA, despite the fact that these are colleges which, at this institution, have reputations for offering robust SL offerings. When analyzing non-underrepresented students only, or underrepresented students and non-underrepresented students together, only half of the colleges (i.e., Biology, Agriculture, and Science and Engineering) showed a positive relationship between SL participation and students' cumulative GPA (see Table 1 and Table 3). In sum, SL was not positively related to students' academic performance in every college, and had negative relations in some instances.

Regarding cumulative units earned, when including both underrepresented and non-

Table 1

The Relationship between SL and Academic Outcomes for the College Students

\begin{tabular}{|c|c|c|c|c|c|c|c|c|c|c|}
\hline & \multicolumn{2}{|c|}{ GPA } & \multicolumn{2}{|c|}{ Units Earned } & \multicolumn{3}{|c|}{ Retention } & \multicolumn{3}{|c|}{ Graduation } \\
\hline & $B$ & $S E$ & $B$ & $S E$ & $B$ & $S E$ & $O R$ & $B$ & $S E$ & $O R$ \\
\hline University $(N=5244)$ & $.08 * * *$ & .01 & -.21 & .66 & $.81 * * *$ & .07 & 2.25 & $.63 * * *$ & .06 & 1.89 \\
\hline \multicolumn{11}{|l|}{ Colleges } \\
\hline Biology $(n=413)$ & $.35 * * *$ & .07 & $11.53 * * *$ & 2.312 & $1.02 * * *$ & .30 & 2.78 & $.46^{*}$ & .23 & 1.58 \\
\hline Design $(n=154)$ & -.07 & .08 & $-6.81 *$ & 3.23 & $1.64 * * *$ & .47 & 5.15 & $1.15^{* *}$ & .43 & 3.16 \\
\hline $\begin{array}{l}\text { Food and Agriculture } \\
\qquad(n=318)\end{array}$ & $.27 * * *$ & .07 & $8.17 *$ & 3.26 & $2.04 * * *$ & .31 & 7.71 & 1.23 & .44 & 2.18 \\
\hline Liberal Arts $(n=2525)$ & -.01 & .02 & $-2.10 *$ & .93 & $1.02 * * *$ & .10 & 2.77 & $.67 * * *$ & .08 & 1.96 \\
\hline $\begin{array}{l}\text { Science and Engineering } \\
\quad(n=871)\end{array}$ & $.10 * *$ & .04 & $3.62 *$ & 1.81 & $1.36^{* * *}$ & .31 & 3.88 & $.88 * * *$ & .18 & 2.42 \\
\hline Management $(n=451)$ & .05 & .04 & -2.41 & 2.11 & $1.04 *$ & .50 & 2.82 & $.85^{* *}$ & .33 & 2.33 \\
\hline
\end{tabular}

Notes. $O R=$ Odds Ratio $*$ p $<.05 ; * * \mathrm{p}<.01 ; * * * \mathrm{p}<.001$

Table 2

The Relationship between SL and Academic Outcomes for Underrepresented Students

\begin{tabular}{|c|c|c|c|c|c|c|c|c|c|c|}
\hline & \multicolumn{2}{|c|}{$G P A$} & \multicolumn{2}{|c|}{ Units Earned } & \multicolumn{3}{|c|}{ Retention } & \multicolumn{3}{|c|}{ Graduation } \\
\hline & $B$ & $S E$ & $B$ & $S E$ & $B$ & $S E$ & $O R$ & $B$ & $S E$ & $O R$ \\
\hline University $(N=2575)$ & $.12 * * *$ & .03 & .54 & 1.73 & $.80 * * *$ & .10 & 2.23 & $.54 * * *$ & .08 & 1.72 \\
\hline \multicolumn{11}{|l|}{ Colleges } \\
\hline Biology $(n=207)$ & $.30 *$ & .12 & $9.76 * *$ & 3.62 & $.86^{*}$ & .37 & 2.36 & .25 & .30 & 1.28 \\
\hline Design $(n=62)$ & $-.32 *$ & .13 & -2.91 & 5.21 & .63 & .78 & 1.87 & 1.06 & .73 & 2.88 \\
\hline $\begin{array}{l}\text { Food and Agriculture } \\
\qquad(n=133)\end{array}$ & $-.29 *$ & .14 & -3.43 & 5.35 & .60 & .80 & 1.82 & .98 & .75 & 2.66 \\
\hline Liberal Arts $(n=1264)$ & $.06^{*}$ & .03 & .59 & 1.49 & $.99 * * *$ & .13 & 2.69 & $.63 * * *$ & .12 & 1.88 \\
\hline $\begin{array}{l}\text { Science and Engineering } \\
\quad(n=311)\end{array}$ & -.02 & .10 & 1.82 & 4.84 & $1.05^{*}$ & .50 & 2.84 & .31 & .28 & 1.36 \\
\hline Management $(n=133)$ & .07 & .09 & -4.17 & 5.49 & .08 & .78 & 1.08 & .53 & .51 & 1.69 \\
\hline
\end{tabular}

Notes. $O R=$ Odds Ratio; $* p<.05 ; * * p<.01 ; * * * p<.001$ 
Table 3

The Relationship between SL and Academic Outcomes for Non-Underrepresented Students

\begin{tabular}{|c|c|c|c|c|c|c|c|c|c|c|}
\hline & \multicolumn{2}{|c|}{ GPA } & \multicolumn{2}{|c|}{ Units Earned } & \multicolumn{3}{|c|}{ Retention } & \multicolumn{3}{|c|}{ Graduation } \\
\hline & $B$ & $S E$ & $B$ & $S E$ & $B$ & $S E$ & $O R$ & $B$ & $S E$ & $O R$ \\
\hline University $(N=2669)$ & $.15 * * *$ & .02 & $11.97 * * *$ & .93 & $.84 * * *$ & .12 & 2.33 & $.76 * * *$ & .09 & 2.13 \\
\hline \multicolumn{11}{|l|}{ Colleges } \\
\hline Biology $(n=206)$ & $.27 * * *$ & .07 & $10.80 * * *$ & 3.09 & $1.55^{* *}$ & .58 & 4.70 & $.81 *$ & .36 & 2.25 \\
\hline Design $(n=92)$ & .05 & .09 & $-9.22 *$ & 4.03 & $2.39 * * *$ & .63 & 10.91 & $1.18 *$ & .54 & 3.26 \\
\hline $\begin{array}{l}\text { Food and Agriculture } \\
\quad(n=185)\end{array}$ & $.33 * * *$ & .07 & $16.58 * * *$ & 4.33 & $1.75^{* * *}$ & .41 & 5.78 & $1.71 * * *$ & .36 & 5.52 \\
\hline Liberal Arts $(n=1261)$ & $-.07 * *$ & .03 & -2.07 & 1.09 & $1.05 * * *$ & .16 & 2.87 & $.71 * * *$ & .12 & 2.03 \\
\hline $\begin{array}{l}\text { Science and Engineering } \\
\quad(n=560)\end{array}$ & $.18 * * *$ & .07 & $6.03 *$ & 2.90 & $1.52 * * *$ & .41 & 4.59 & $1.24 * * *$ & .24 & 3.46 \\
\hline Management $(n=318)$ & .05 & .07 & -1.79 & 3.08 & $1.66^{*}$ & .75 & 4.23 & $1.03^{*}$ & .43 & 2.80 \\
\hline
\end{tabular}

Notes. $O R=$ Odds Ratio $* *^{*} p .05 ; * * p<.01 ; * * * p<.001$

underrepresented students, three of the colleges (i.e., Biology, Agriculture, and Science and Engineering) showed positive SL relationships with the same result for non-underrepresented students only. Among underrepresented students, only those from Biology benefited from participating in SL courses. Other colleges did not show any difference in cumulative units earned between students who participated in SL courses and those who did not. In the colleges of Science and Engineering and Design, the relationship between students' SL participation with their units earned were negative (see Table 1). In sum, our analyses of within-college outcomes revealed mixed results regarding SL's relationship with units earned.

Regarding retention rates, when analyzing underrepresented and non-underrepresented students together, all colleges showed that SL participants had a higher likelihood of continuing enrollment at college in the fourth year. However, for underrepresented students, this was significant for only three of the colleges (i.e., Biology, Liberal Arts, and Science and Engineering) (see Table 2). For nonunderrepresented students, SL participation was positively related to retention in all six colleges (see Table 3). This finding suggests a less robust, consistent positive effect of SL on underrepresented students' retention.

When comparing the overall graduation rates of students (both underrepresented and nonunderrepresented students) who participated in SL with those who did not, our study found that students who participated in SL were more likely to graduate after four years than the non-SL students in all but one college (Agriculture) (see Table 1). Non-underrepresented students who participated in SL showed a higher likelihood of graduation after four years for all six colleges, when compared to non-underrepresented students who did not partici- pate in SL. However, among underrepresented students, only those from the college of Liberal Arts showed a positive relationship between SL participation with graduation rates $(B=.63, p<.001)$ when contrasted with comparable underrepresented students who did not participate in SL. Again, this finding suggests a less robust, consistent positive relationship for underrepresented students.

Overall, there was a consistent beneficial relationship of SL with students' fourth-year educational outcomes for both underrepresented and non-underrepresented students throughout the university. However, SL's relationship with retention and graduation were less clear when we analyzed underrepresented students' outcomes within colleges. In comparison to the effects of SL for non-underrepresented students, underrepresented students had fewer and less consistent positive relationships with retention and graduation rates across the colleges. Overall, regardless of student status (i.e., underrepresented, non-underrepresented), SL's relationship with students' cumulative GPA and units earned were mixed; negative or positive effects of SL participation were dependent on the college in which students were enrolled.

\section{Discussion}

The present study investigated whether college students, especially underrepresented students, who participated in service-learning (SL) demonstrated higher levels of academic performance (i.e., better cumulative GPA) and higher levels of persistence (i.e., higher cumulative units earned, retention, and graduation) when contrasted with non-SL peers. Examining the university-wide effectiveness of SL, there were positive relationships between SL course taking and underrepresented students' GPA, retention, and graduation rates, but not for units 
earned. Examining college-level SL relationships, results showed significant differences between SL students and non-SL students in fourth-year retention and graduation rates for all colleges for nonunderrepresented students; however, the effectiveness of SL on underrepresented students' retention and graduation rates were found in only some of the colleges. SL had inconsistent relationships with GPA and units earned across colleges for both underrepresented and non-underrepresented students. Taken together, even though SL courses promoted university-wide educational success for both underrepresented and non-underrepresented students, within colleges SL courses were less consistently related to positive academic outcomes for underrepresented students than for non-underrepresented students, particularly in terms of retention and graduation rates.

The university-wide relationship between SL and students' educational success (i.e., higher GPA and persistence) found in the present study is consistent with previous research (Bringle, Hatcher, \& Muthiah, 2010, Celio, Durlak, \& Dymnicki, 2011; Gallini \& Moely, 2003; Lockeman \& Pelco, 2013; Reed, Rosenberg, Statham, \& Rosing, 2015; Warren, 2012; Yorio \& Ye, 2012). The findings also partially support our hypothesis that participation in SL can promote the educational success of underrepresented students. The findings suggest that SL can be a powerful tool to promote students' overall engagement with college and community since it provides a chance for students to link academic knowledge and theory learned in the classroom to the practical issues in the community. Increased engagement contributes to higher levels of involvement and development of a sense of belonging to the school, which in turn, mediate increased graduation rates and retention.

The discrepancy between underrepresented and non-underrepresented students with regard to the relationships between SL and retention and graduation indicates that participation in SL courses does not always produce positive results, nor does it affect all students equally. In their comparative study, Lockeman and Pelco (2013) found that the SL participants (including those with greater financial need) were able to earn more credits and have higher GPAs than non-SL participants. However, they found no differences in outcomes between underrepresented students (in this case, students from low-income backgrounds) who participated in SL and non-underrepresented students who participated in SL.

There are many potential explanations as to why participation in SL (a purported high impact practice) might not produce significantly more positive outcomes for underrepresented students as some of the SL literature suggests. First, as we described previously, underrepresented students face more challenges in college than their peers, which in turn could interfere with their full participation in SL. For instance, low-income students are more likely to have multiple obligations outside of school, such as a part/full-time jobs, and spend less time in service activities (Engle \& Tinto, 2008). Second, SL programs have been criticized for not specifically aligning programming with needs of underrepresented students. Currently, SL experiences tend to be largely designed by White faculty and serve White students, who are less likely to be lowincome and first-generation (Mitchell, Donahue, \& Young-Law, 2012). Such programs may be structured with the assumption that the participating students will be unfamiliar with the community with which they will partner, and thus engage students in boundary-crossing experiences. However, for underrepresented students who are already comfortable in such communities, the boundary-crossing goals of the SL might not be realized, resulting in a less effective growth experience for them. In addition, teaching and instruction likely reinforce norms and values developed by a majority White population, which might resonate less for students from minority populations. When framing social problems and discussion, instructors can often overlook the meaning underrepresented students make from service to their own unique backgrounds. This may discourage disclosure and open discussion among students and between students and faculty, and curtail students' full engagement in SL and the full suite of benefits it can produce.

The findings of our study reveal differences in predictive values of SL with students' academic performance across the six participating colleges. This finding is in line with the results of Reed et al.'s (2015) investigation of SL student impacts, which identified differences in outcomes across the three institutions (two public and one private) they studied. Reed et al.'s study found that while students who participated in SL courses were more likely than non-SL students to persist at all three institutions, the effect was stronger at the two public institutions with the lower overall persistent and entrance selectivity rates. Reed et al. concluded that the differences in outcomes across the institutions were likely due to the differences in the particular disciplines and departments within the institutions that offered SL.

Similar to Reed et al.'s study, our investigation found a negative relationship between underrepresented students' SL participation and their educational success in two of the six colleges. Interest- 
ingly, the negative relationships were found among two of the university's colleges (Agriculture and Design) that maintain a reputation for having a strong culture of student community engagement and service-learning. This particular finding contradicts previous research, which has found that stronger institutional commitments to SL are associated with higher levels of student persistence and degree completion (Lockeman \& Pelco, 2013). In addition to the reasons noted by Reed et al. (2015), we posit that the lack of positive findings our study revealed for two of the six colleges is likely due to the particular ways in which SL is practiced (e.g. quality, intensity, and duration of the service activities) within a college. Previous studies have found that different types of SL have shown to have differential impacts on students' academic outcomes (Parker-Gwin \& Mabry, 1998; Vogelgesang \& Astin, 2000). Unfortunately, without the ability to know which practices were being incorporated into the various SL courses within each college, we were not able to ascertain with confidence that all of the courses incorporated the elements of best practice (e.g., fidelity of treatment) that are recommended in the SL literature (e.g. reflection, meaningful service, sufficient duration). It is likely that the ways these elements are incorporated into the different colleges' SL programs moderate the impacts and expected effects of SL.

Regarding the relationship between SL and GPA, empirical evidence from previous studies has revealed mixed results (Eyler et al., 2001). Astin (1993) argued that grades are not a perfect measure of learning because they reflect a student's performance relative to other students, and are not a measure of how much this student has learned (Pascarella \& Terenzini, 2005). Therefore, fourthyear cumulative GPA may not accurately reflect students' learning gains after taking SL courses. In contrast to York's (2016) study, which found a positive relationship between underrepresented students' participation in SL and their overall GPA, our study findings are more consistent with Lockeman \& Pelco's (2013) investigation, which found that students' participation in SL is not correlated with their year to year GPA. Lockeman and Pelco concluded that service-learning's impact on degree completion is independent of the influence of students' GPA.

In sum, the findings in the current study supports the hypothesis that SL has the potential to enhance students' academic performance and college persistence, and that depending on the specific institutional culture, it can promote the educational success of underrepresented students (Cushman, 2007). However, the presence of less positive ef- fects of SL for underrepresented students, in certain circumstances, might also indicate that these students experience SL courses differently from their majority counterparts. Thus, it is important to consider the extent to which SL courses are tailored to meet the different needs of diverse student bodies. Faculty members can structure classroom activities in ways that require students to become more involved in the learning process by working with their peers through cooperative and problem-based learning - pedagogies that can improve student engagement and success (Braxton et al, 2000). There is a need to examine further how SL is experienced by different groups of students (Green, 2003). Recognition of these differences can help optimize positive experiences of underrepresented students, and all students, in SL courses.

\section{Limitations and Future Research Directions}

The current study had several limitations. First, the present research only examined the relationship between students' SL participation and their fourthyear outcomes. This limited the analysis and understanding of the progression of student growth. In the present study, students were flagged as having participated in SL without our knowledge of when they took SL courses. Without knowing when students engaged in SL, we could not separate out the more immediate from the longer-term effects of SL. Research has suggested that intervention programs, such as SL, are especially effective during the first semester for academically underprepared students (Weissman, Silk, \& Bulakowski, 1997). Other research suggests that more intensive SL participation and the number of credits earned through SL experiences are positively correlated with academic performance and degree completion (Lockeman \& Pelco, 2013; Rochford, 2014). It is possible that there is a more extensive and robust relationship between SL participation and students' academic outcomes and persistence in the short term, such as semester to semester or year to year. For example, a study by Bringle, Hatcher, and Muthiah (2010) found that enrollment in SL among the first-year students was related to re-enrollment the following year, suggesting more and better SL courses during the first year may be able to produce stronger and more robust effects on persistence. If students participated in SL in their junior or senior year, SL may show weaker relationships with educational success compared to those of SL courses taken in the freshman year, and/or if more courses that contained SL were taken. Future studies should look at changes in GPA after participation in SL and examine whether earlier and greater participation in SL makes any difference. Examining 
the relationship between students' SL participation and their academic attainment and persistence based on when students first took SL courses could also help distinguish between short and long-term effects of SL.

Second, the present study relied on secondary data collected through the university's institutional research office. While these data provided us with a large, low-cost data set, afforded us the full support of the institutional research office (e.g., being able to flag students who participated in SL and those who did not), and allowed us to explore the relationship between SL and academic achievement, it limited our ability to conduct certain analyses that we would have liked to have conducted. For example, although the literature suggests that the level of students' engagement in learning is a mediator of service-learning's impact on students' achievement (Gallini \& Moely, 2003), we were not able to gather engagement levels from the student sample. Therefore, we were not able to test this mediation with our sample.

Third, the present study found that SL was less related to academic outcomes for underrepresented students compared to other students. In part, that reflects the smaller sample in the latter group, but differences are not always in the same direction. Because of limitations in the data that were available to us, we are not able to explore further the factors that may have led to this result. Yeh's (2010) study of the potential impact of SL on underrepresented students' retention hypothesized four areas of impacts: (a) building skills and understanding, (b) developing resiliency, (c) finding personal meaning, and (d) developing critical consciousness. We did not have data to examine the extent to which SL promotes or hinders development of these underlying skills in underrepresented students. To understand the reason why SL did not boost underrepresented students' educational success as much as for other students, future studies need be conducted to discover if, for underrepresented students, SL is related to the predictors of educational success, such as those identified by Yeh (2010).

A fourth limitation is that we had initially disaggregated the data to analyze the different variables pertaining to underrepresented status (e.g. ethnicity/race, Pell, first generation). However, due to relatively small sample sizes for four of the colleges, robust analyses could not be completed for some underrepresented categories. For instance, the Design college had only 63 underrepresented students, and therefore, disaggregating the data into three different subgroups (ethnicity/race, Pell Grant eligibility, first generation) would not have provided a sufficient sample to conduct a robust analysis.
In addition, we found that most of the underrepresented students in the sample fell into more than one underrepresented subgroup (e.g. a student can be both first generation and Pell eligible). Consequently, establishing subgroups based on one underrepresented variable would result in overlapping groups (same student in more than one subgroup), and, in turn, hinder our ability to assess the unique impact of each subgroup variable.

\section{Conclusion}

The results presented in the present study show promise for future research. We applied propensity score matching (PSM) methods - full matching - to create comparable groups, which minimized selfselection bias. Positive relationships were found at the institutional level between participation in SL courses during college years and students' educational outcomes. Our findings suggest that SL has great potential for enhancing underrepresented students' academic success, regardless of when the students enroll in the SL courses during four college years. Within individual colleges, SL participation seems to benefit non-underrepresented students more than underrepresented students with respect to the retention and four-year graduation rates. It would be beneficial to consider the particular needs of underrepresented students when SL courses are being designed and developed. Overall, by using propensity score matching to strengthen group equivalence between the treatment and comparison groups, our study offers empirical evidence regarding some of the potential impacts of SL on underrepresented students' educational success and persistence. Additional empirical research on this issue can provide a better understanding of the full range of potential benefits SL holds for today's underrepresented students. Our next step is to examine students' SL participation in the different academic years, and to assess whether early SL participation promotes better overall college success than later participation.

\section{Note}

${ }^{1}$ The academic-related skills include study skills and habits, time-management skills, coping strategies, problem solving skills, leadership and communication skills (Robbins, Lauve, Le, Davis, Langley, \& Carlstrom, 2004).

\section{References}

Astin, A. W. (1993). What matters in college? Four critical years revisited. San Francisco: Jossey-Bass. 
Astin, A. W., \& Sax, L. J. (1998). How undergraduates are affected by service participation. Service Participation, 39(3), 251-263

Astin, A. W., \& Oseguera, L. (2005). Pre-college and institutional influences on degree attainment. College student retention: Formula for student success, 245276.

Astin, A. W., Vogelgesang, L. J., Ikeda, E. K., \& Yee, J. A. (2000). How service-learning affects students. Los Angeles: University of California, Higher Education Research Institute.

Austin, P. C., \& Stuart, E. A. (2015). The performance of inverse probability of treatment weighting and full matching on the propensity score in the presence of model misspecification when estimating the effect of treatment on survival outcomes. Statistical Methods in Medical Research, 26(4), 1-21.

Batchelder, T. H., \& Root, S. (1994). Effects of an undergraduate program to integrate academic learning and service: Cognitive, prosocial cognitive, and identity outcomes. Journal of Adolescence, 17(4), 341-355.

Bean, J. P. (1980). Dropouts and turnover: The synthesis and test of a causal model of student attrition. Research in Higher Education, 12(2), 155-187.

Bean, J. P. (1983). The application of a model of turnover in work organizations to the student attrition process. Review of Higher Education, 6(2), 129-148.

Bean, J., \& Eaton, S. B. (2001). The psychology underlying successful retention practices. Journal of College Student Retention: Research, Theory \& Practice, 3(1), 73-89.

Berger, J. B., \& Milem, J. F. (1999). The role of student involvement and perceptions of integration in a causal model of student persistence. Research in Higher Education, 40(6), 641-664.

Bernacki, M. L., \& Jaeger, E. (2008). Exploring the impact of service-learning on moral development and moral orientation. Michigan Journal of Community Service Learning, 14(2), 5-15.

Boss, J. A. (1994). The effect of community service work on the moral development of college ethics students. Journal of Moral Education, 23(2), 183-198.

Boyle-Baise, M., \& Kilbane, J. (2000). What really happens? A look inside service-learning for multicultural teacher education. Michigan Journal of Community Service Learning, 7(1), 54-64.

Braxton, J. M., Shaw Sullivan, A. V., \& Johnson, R. M. (1997). Appraising Tinto's theory of college student departure. In J.C. Smart (Ed.), Higher education: Handbook of theory and research, Vol. 12 (pp. 107164). New York: Agathon Press.

Bridges, B. K., Kinzie, J., Nelson Laird, T. F., and Kuh, G. D. (2008) Student engagement and success at Minority Serving Institutions. In M. Gasman, B. Baez, \& C.S.V. Turner (Eds.), Understanding minority-serving institutions. Albany, NY: SUNY Press.

Bringle, R. G., \& Hatcher, J. A. (1996). Implementing service learning in higher education. The Journal of Higher Education, 67(2), 221-239.

Bringle, R. G., Hatcher, J. A., \& Muthiah, R. N. (2010).
The role of service-learning on the retention of firstyear students to second year. Michigan Journal of Community Service Learning, 16(2), 38-49.

Brofenbrenner, U. (1979). The ecology of human development: Experiments by nature and design. Cambridge, MA: Harvard University Press.

Celio, C. I., Durlak, J., \& Dymnicki, A. (2011). A metaanalysis of the impact of service-learning on students. Journal of Experiential Education, 34(2), 164-181.

Chesler, M., \& Scalera, C. V. (2000). Race and gender issues related to service-learning research. Michigan Journal of Community Service Learning, Special Issue, 18-27.

Conway, J. M., Amel, E. L., \& Gerwien, D. P. (2009). Teaching and learning in the social context: A metaanalysis of service learning's effects on academic, personal, social, and citizenship outcomes. Teaching of Psychology, 36(4), 233-245.

Cook, T. D. (2002). Randomized experiments in educational policy research: A critical examination of the reasons the educational evaluation community has offered for not doing them. Educational Evaluation and Policy Analysis, 24(3), 175-199.

Corbett, J. B., \& Kendall, A. R. (1998). Evaluating service learning in the communication discipline. Journalism \& Mass Communication Educator, 53(4), 6676.

Cushman, K. (2007). Facing the culture shock of college. Educational Leadership, 64(7), 44-47.

Curran, J. M. (1998). College students' attitudes towards mental retardation: A pilot study. Paper presented at the annual meeting of the American Psychological Association, San Francisco, CA.

d'Agostino, R. B. (1998). Tutorial in biostatistics: propensity score methods for bias reduction in the comparison of a treatment to a non-randomized control group. Statistics in Medicine, 17(19), 2265-2281.

Dennis, J. M., Phinney, J. S., \& Chuateco, L. I. (2005). The role of motivation, parental support, and peer support in the academic success of ethnic minority first-generation college students. Journal of College Student Development, 46(3), 223-236.

DesJardins, S. L., Kim, D. O., \& Rzonca, C. S. (2003). A nested analysis of factors affecting bachelor's degree completion. Journal of College Student Retention: Research, Theory \& Practice, 4(4), 407-435.

Engle, J., \& Tinto, V. (2008). Moving beyond access: College success for low-income, first-generation students. Pell Institute for the Study of Opportunity in Higher Education. Retrieved from http://files.eric. ed.gov/fulltext/ED504448.pdf

Eyler, J., \& Giles Jr, D. E. (1999). Where's the learning in service-learning? San Francisco: Jossey-Bass.

Eyler, J. S., Giles, Jr. D. E., Stenson, C. M., \& Gray, C.J. (2001). At a Glance: What we know about the effects of service-learning on college students, faculty, institutions and communities, 1993-2000 (3rd ed.). Nashville, TN: Vanderbilt University. Retrieved from http:// www.compact.org/wp-content/uploads/resources/ downloads/aag.pdf 
Flournoy, C. (2007). Doing learning: Investigative reporting and service learning. Journalism \& Mass Communication Educator, 62(1), 47-61.

Frisco, M. L., Muller, C., \& Frank, K. (2007). Parents' union dissolution and adolescents' school performance: Comparing methodological approaches. Journal of Marriage and Family, 69(3), 721-741.

Fuertes, J. N., \& Sedlacek, W.E. (1994). Using the SAT and noncognitive variables to predict the grades and retention of Asian American university students. Measurement \& Evaluation in Counseling \& Development, 27(2), 74-85.

Furco, A., Jones-White, D., Huesman Jr, R., \& Gorny, L. S. (2016). Modeling the influence of service-learning on academic and sociocultural gains: Findings from a multi-institutional study. In K. Soria \& T.D. Mitchell (Eds.), Civic engagement and community service at research universities (pp. 143-163). London: Palgrave Macmillan UK.

Gallini, S. M., \& Moely, B. E. (2003). Service-learning and engagement, academic challenge, and retention. Michigan Journal of Community Service Learning, 10(1), 5-14.

Goodman, K., \& Pascarella, E. T. (2006). First-year seminars increase persistence and retention: Evidence from how college affects students. Peer Review: Emerging Trends and Key Debates in Undergraduate Education. The Association of American Colleges and Universities, 8(3), 26-28.

Green, A. E. (2001). "But you aren't white:" Racial perceptions and service-learning. Michigan Journal of Community Service Learning, 8(1), 18-26.

Greenberg, J. S. (1997). Service-learning in health education. Journal of Health Education, 28(6), 345-349.

Hansen, B. B. (2004). Full matching in an observational study of coaching for the SAT. Journal of the American Statistical Association, 99(467), 609-618.

Ho, D. E., Imai, K., King, G., \& Stuart, E. A. (2007). Matching as nonparametric preprocessing for reducing model dependence in parametric causal inference. Political Analysis, 15(3), 199-236.

Hurtado, S., Carter, D. F., \& Spuler, A. (1996). Latino student transition to college: Assessing difficulties and factors in successful college adjustment. Research in Higher Education, 37(2), 135-157.

Hurtado, S., Milem, J. F., Clayton-Pederson, A., \& Allen, W. (1998). Enhancing campus climates for racial/ethnic diversity: Educational policy and practice. Review of Higher Education, 21(3), 279-302

Jacoby, B. \& Associates. (1996). Service-learning in higher education: Concepts and practices. San Francisco: Jossey-Bass.

Jay, G. (2008). Service learning, multiculturalism, and the pedagogies of differences. Pedagogy, 8(2), 255281.

Johnson, S. C., \& Arbona, C. (2006). The relation of ethnic identity, racial identity, and race-related stress among African American college students. Journal of College Student Development, 47(5), 495-507.

Kelly, P. J. (2013). A framework for service learning in physician assistant education that fosters cultural competency. The Journal of Physician Assistant Education, 24(2), 32-37.

Kuh, G. D. (2003). What we're learning about student engagement from NSSE: Benchmarks for effective educational practices. Change: The Magazine of Higher Learning, 35(2), 24-32.

Kuh, G. D., Cruce, T. M., Shoup, R., Kinzie, J., \& Gonyea, R. M. (2008). Unmasking the effects of student engagement on first-year college grades and persistence. Journal of Higher Education, 79(5), 540-563.

Kuh, G. D., Kinzie, J., Schuh, J. H., Whitt, E. J., \& Associates. (2005). Student success in college: Creating conditions that matter. San Francisco: Jossey-Bass.

Lavin, D. E., \& Crook, D. B. (1990). Open admissions and its outcomes: Ethnic differences in long-term educational attainment. American Journal of Education, 98(4), 389-425.

Lee, S. Y., Olszewski-Kubilius, P., Donahue, R., \& Weimholt, K. (2008). The civic leadership institute: A service-learning program for academically gifted youth. Journal of Advanced Academics, 19(2), 272308.

Lockeman, K. S. (2013) \& Pelco, L.E (2013). The relationship between service-learning and degree completion. Michigan Journal of Community Service Learning, 20(1), 18-30.

Lohfink, M. M., \& Paulsen, M. B. (2005). Comparing the determinants of persistence for first-generation and continuing-generation students. Journal of College Student Development, 46(4), 409-428.

Lopez, G. (2001). The value of hard work: Lessons on parent involvement from an (im) migrant household. Harvard Educational Review, 71(3), 416-438.

McCall, R. B., \& Green, B. L. (2004). Beyond the methodological gold standards of behavioral research: Considerations for practice and policy. Society for Research in Child Development, 18(2), 3-19

McKay, V. C., \& Estrella, J. (2008). First-generation student success: The role of faculty interaction in service learning courses. Communication Education, 57(3), 356-372.

Moely, B. E., Mercer, S. H., Ilustre, V., Miron, D., \& McFarland, M. (2002). Psychometric properties and correlates of the Civic Attitudes and Skills Questionnaire (CASQ): A measure of students' attitudes related to service-learning. Michigan Journal of Community Service Learning, 8(2), 15-26.

Nunez, A. M. (2009). A critical paradox? Predictors of Latino students' sense of belonging in college. Journal of Diversity in Higher Education, 2(1), 46-61.

Novak, J. M., Markey, V., \& Allen, M. (2007). Evaluating cognitive outcomes of service learning in higher education: A meta-analysis. Communication Research Reports, 24(2), 149-157.

Mitchell, T. D., Donahue, D. M., \& Young-Law, C. (2012). Service learning as a pedagogy of whiteness. Equity \& Excellence in Education, 45(4), 612-629.

Parker-Gwin, R., \& Mabry, J. B. (1998). Service learning as pedagogy and civic education: Comparing out- 
comes for three models. Teaching Sociology, 26(4), 276-291.

Pascarella, E. T., Pierson, C. T., Wolniak, G. C., \& Terenzini, P. T. (2004). First-generation college students: Additional evidence on college experiences and outcomes. Journal of Higher Education, 75(3), 249-284.

Pascarella, E. T., \& Terenzini, P. T. (2005). How college affects students: A third decade of research (Vol. 2). San Francisco: Jossey-Boss.

Phinney, J. S. (1993). A threestage model of ethnic identity development in adolescence. In M. Bernal \& G. Knight (Eds.). Ethnic identity: Formation and transmission among Hispanics and other minorities (pp. 6179). Albany, NY: SUNY Press.

Phinney, J. S., Dennis, J., \& Osorio, S. (2006). Reasons to attend college among ethnically diverse college students. Cultural Diversity and Ethnic Minority Psychology, 12(2), 347-366.

Reed, S. C., Rosenberg, H., Statham, A., \& Rosing, H. (2015). The effect of community service learning on undergraduate persistence in three institutional contexts. Michigan Journal of Community Service Learning, 21(2), 22-36.

Robbins, S. B., Lauver, K., Le, H., Davis, D., Langley, R., \& Carlstrom, A. (2004). Do psychosocial and study skill factors predict college outcomes? A metaanalysis. Psychological Bulletin, 130(2), 261-28

Rodriguez, N., Mira, C. B., Myers, H. F., Morris, J. K., \& Cardoza, D. (2003). Family or friends: Who plays a greater supportive role for Latino college students? Cultural Diversity and Ethnic Minority Psychology, 9(3), 236-250.

Rosenbaum, P. R., \& Rubin, D. B. (1985). Constructing a control group using multivariate matched sampling methods that incorporate the propensity score. The American Statistician, 39(1), 33-38.

Ryan, C. L., \& Bauman, K. (2016). Educational attainment in the United States: 2015 (No. P20-578) (pp. 1-11). United States Census Bureau. Retrieved from http://www.census.gov/content/dam/Census/library/ publications/2016/demo/p20-578.pdf

Simons, L., \& Cleary, B. (2006). The influence of service learning on students' personal and social development. College Teaching, 54(4), 307-319.

Spence, J. T., Pred, R. S., \& Helmreich, R. L. (1989). Achievement strivings, scholastic aptitude, and academic performance: A follow-up to" Impatience versus achievement strivings in the Type A pattern." Journal of Applied Psychology, 74(1), 176-178.

St. Louis, G. R., \& Liem, J. H. (2005). Ego identity, ethnic identity, and the psychosocial well-being of ethnic minority and majority college students. Identity, 5(3), 227-246.

Steinke, P., \& Buresh, S. (2002). Cognitive outcomes of service-learning: Reviewing the past and glimpsing the future. Michigan Journal of Community Service Learning, 8(2), 5-14.

Stewart, T. (2008). Comparing the intended and the perceived: Administrator expectations and student perceptions of teacher roles in Catholic service-learning. The
High School Journal, 91(4), 59-76.

Stuart, E. A. (2010). Matching methods for causal inference: A review and a look forward. Statistical Science: A Review Journal of the Institute of Mathematical Statistics, 25(1), 1-21.

Stuart, E. A., \& Green, K. M. (2008). Using full matching to estimate causal effects in nonexperimental studies: Examining the relationship between adolescent marijuana use and adult outcomes. Developmental Psychology, 44(2), 395-406.

Taylor, C. M., \& Howard-Hamilton, M. F. (1995). Student involvement and racial identity attitudes among African American males. Journal of College Student Development, 36, 330-330.

Terenzini, P.T., Cabrera, A.F., \& Bernal, E.M. (2001). Swimming against the tide: The poor in American higher education. New York: College Board.

Terenzini, P. T., Springer, L., Yaeger, P. M., Pascarella, E. T., \& Nora, A. (1996). First-generation college students: Characteristics, experiences, and cognitive development. Research in Higher Education, 37(1), $1-22$.

Thayer, P. (2000). Retention of students from first generation and low income backgrounds. Journal of the Council for Opportunity in Education, 3(1), 2-8.

Tinto, V. (Ed.). (1993). Leaving college: Rethinking the causes and cures of student attrition Chicago: University of Chicago Press.

Tinto, V. (2003, November). Promoting student retention through classroom practice. Paper presented at the international conference on Enhancing Student Retention: Using International Policy and Practice, sponsored by the European Access Network and the Institute for Access Studies. Amsterdam, The Netherlands.

Tseng, V. (2004). Family interdependence and academic adjustment in college: Youth from immigrant and U.S.born families. Child Development, 75(3), 966-983.

Turner, C. S. V. (1994). Guests in someone else's house: Students of color. Review of Higher Education, 17(4), 355-370.

Vogelgesang, L. J., \& Astin, A. W. (2000). Comparing the effects of community service and servicelearning. Michigan Journal of Community Service Learning, 7(1), 25-34.

Warren, J. L. (2012). Does service-learning increase student learning?: A meta-analysis. Michigan Journal of Community Service Learning, 18(2), 56-61.

Wasley, P. (2006). Underrepresented students benefit most from 'engagement'. Chronicle of Higher Education, 53(13), A39-A40.

Weissman, J., Silk, E., \& Bulakowski, C. (1997). Assessing developmental education policies. Research in Higher Education, 38(2), 187-200.

Yeh, T. L. (2002). Asian Americans college students who are educationally at risk, New Directions for Student Services, Special Issue, 61-71.

Yeh, T. L. (2010). Service-learning and persistence of low-income, first-generation college students: An exploratory study. Michigan Journal of Community Ser- 
vice Learning, 16(2), 50-65.

Yorio, P. L., \& Ye, F. (2012). A meta-analysis on the effects of service-learning on the social, personal, and cognitive outcomes of learning. Academy of Management Learning \& Education, 11(1), 9-27.

York, T.T. (2016). Exploring service-learning outcomes and experiences for low-income, first-generation college students: A mixed-methods approach. International Journal for Research on Service-Learning and Community Engagement, 4(1), 209-342

Zalaquett, C. P. (1999). Do students of noncollegeeducated parents achieve less academically than students of college-educated parents? Psychological Reports, 85(2), 417-421.

\section{Authors}

WEI SONG (songx596@umn.edu) is a Ph.D. candidate of educational psychology at the University of Minnesota. Her research interests include the social relationships and socioemotional development during childhood and adolescence, as well as the role of community engagement in students' educational success and personal development.

ANDREW FURCO (afurco@umn.edu) is pro- fessor of higher education at the University of Minnesota, where he also serves as associate vice president for public engagement. His research focuses on investigating the impacts, implementation, and institutionalization of service-learning and community engagement in K-12 and higher education, both in the U.S. and abroad.

ISABEL LOPEZ (lopez632@umn.edu) is a Ph.D. student of educational psychology at the University of Minnesota. Her research interests include social-psychological interventions in higher education which promote student academic achievement and wellbeing as well as the role of service-learning in underrepresented students' academic success in higher education.

GEOFFREY MARUYAMA (Geoff@umn.edu) is chair and professor of educational psychology at the University of Minnesota. His research has focused on achievement and attainment processes in schools, on research methods for educational and other applied settings, and on action research approaches and engaged scholarship in challenged communities. 